\title{
ФИЗИКОХИМИЯ МОРСКОГО СОЛЕВОГО АЭРОЗОЛЯ
}

\author{
В.Я. Хентов ${ }^{1}$, В.М. Гасанов ${ }^{1}$, К.Е. Сёмина ${ }^{2}$, Е.Г. Сёмин ${ }^{2 *}$
}

${ }^{1}$ Южно-Российский государственный политехнический университет им. М.И. Платова (Новочеркасск) и

${ }^{2}$ Санкт-Петербургский государственный политехнический университет (Санкт-Петербург), Россия

* Эл.nочma: egsemin@gmail.com

Статья поступила в редакичю 09.08.2014; принята к печати 10.11.2014

Рассмотрены способы генерации пузырей газа и их всплывание в жидкости (барботаж), образование газожидкостных систем и их свойства. Основное внимание уделено разрыву пузырей на поверхности жидкости, образованию барботажного аэрозоля и селективности этого процесса. Предложены механизмы разделения ионов при образовании кумулятивных капель. Показано, что упорядочивание структуры воды приводит к увеличению времени жизни свободных жидкостных пленок. Ионы жидкости кумулятивных капель теряют часть избыточного заряда, который распределяется по всей массе жидкости. В этом случае можно говорить об образовании гидратированных электронов и свободных молекул (хлора, брома, йода). Кроме дисбаланса адсорбции ионов и сброса избыточного заряда приводятся и другие механизмы появления свободных галогенов: в результате радиоактивного распада изотопа ${ }^{40}$ п при воздействии космического и ультрафиолетового излучения, а также под действием квантов света. Сделана оценка энергии выхода ионов из раствора. В реальных условиях в воздухе зафиксировано появление свободных галогенов. Эти явления играют важную роль во взаимодействии океан-атмосфера, образовании ядер конденсации и облаков, химического состава выпадающих осадков. С капельным уносом связано заряжение атмосферы над океаном. С кумулятивными каплями с водной поверхности удаляются углеводородные пленки, коллоидные частицы и частицы суспензий, легко переносятся микроорганизмы. В присутствии электролита процесс удаления дисперсных частиц с кумулятивными каплями усиливается. Барботажный аэрозоль создает серьезные экологические и технические проблемы, которые приходится учитывать при проведении ряда технологических процессов.

Ключевые слова: морской солевой аэрозоль, капельный унос, разделение ионов, барботаж.

\author{
PHYSICAL CHEMISTRY OF SEA-SALT AEROSOL \\ V.Ya. Khentov ${ }^{1}$ V.M. Gasanov ${ }^{1}$, K.Ye. Semina ${ }^{2}$, Ye.G. Semin ${ }^{2 *}$ \\ ${ }^{1}$ I.M. Platonov South-Russia Polytechnic University (Novocherkassk) and ${ }^{2}$ Saint-Petersburg Polytechnic \\ University (Saint Petersburg), Russia \\ *E-mail:egsemin@gmail.com
}

Gas bubble generation and heaving in a liquid (bubbling) and the resulting gas-liquid system formation and properties are discussed with special emphasis on bubble rupture at the surface of a liquid and on bubble-generated aerosol formation and the selectivity of this process. Mechanisms of ion separation upon cumulative drop formation are proposed. Increasing structuring of water has been shown to increase the lifetime of free liquid films. Ions in the liquid of a cumulative drop loose a part of their excess charge, which becomes distributed throughout the entire amount of the liquid. In this case, it reasonable to think about the formation of hydrated electrons and free molecules (chlorine, bromine, and iodine). Besides this imbalance between ion adsorption and excess charge release, other possible mechanisms of free halogen formation include radioactive ${ }^{40} \mathrm{~K}$ decay under the impacts of cosmic and $\mathrm{UV}$ radiation and of photons. The energy of ion release from a solution is estimated. The appearance of free halogens in the air has indeed been detected in nature. These phenomena are important in interactions between the sea and the atmosphere, in the formation of condensation nuclei and clouds, and in the building up of the chemical composition of atmospheric precipitates. Droplet entrainment is associated with charging of the atmosphere above the sea. Cumulative droplets can remove hydrocarbon films and colloidal and suspended particles from water surface and serve as a vehicle for microorganisms. The presence of electrolytes enhances the removal of dispersed particles by cumulative drops. Bubble-generated aerosol is responsible for serious ecological and technical problems, which must be accounted of in a number of technologies.

Keywords: sea-salt aerosol, droplet entrainment, ion separation, bubbling.

В формировании климата Земли одну из важных ролей играют радиационные факторы, влияние которых тесно связано с содержанием аэрозолей в атмосфере $[6,10]$. Атмосфера Земли содержит твердые и жидкие аэрозольные частицы. Твердые частицы имеют антропогенное и промышленное происхождение. Жидкие аэрозоли формируются из морской воды (морской аэрозоль) и в результате конденсации водяного пара на ядрах конденсации. В табл. 1 представлены основные механизмы формирования аэрозолей [10]. Мелкодисперсная фаза морского аэрозоля играет важнейшую роль в радиационном балансе атмосферы, то есть в формировании погоды и климата.

Основные механизмы формирования аэрозолей

\begin{tabular}{|l|l|}
\hline \multicolumn{1}{|c|}{ Тип аэрозоля } & \multicolumn{1}{c|}{ Механизм формирования аэрозоля } \\
\hline Почвенно-эрозионный & Физический процесс ветровой эрозии \\
\hline Морской & Брызги гребней волн \\
& Разрыв пузыря и образование капель \\
\hline Из газовой фазы & Газо-химические реакции - образование кластеров \\
\hline
\end{tabular}


По размерам аэрозольные частицы подразделяются на три класса (табл. 2) [8].

\section{Классификация аэрозольных частиц по размерам}

\begin{tabular}{|l|c|}
\hline \multicolumn{1}{|c|}{ Класс аэрозольных частиц } & Размеры (r, мкм) \\
\hline Мелкодисперсные & $r \leq 0,1$ \\
\hline $\begin{array}{l}\text { Среднедисперсные } \\
\text { (большие частицы) }\end{array}$ & $0,1<r<1,0$ \\
\hline $\begin{array}{l}\text { Грубодисперсные } \\
\text { (гигантские частицы) }\end{array}$ & $r \geq 1,0$ \\
\hline
\end{tabular}

Морской аэрозоль вызывает повышенный интерес в связи с проявлением особых свойств капельножидкой фазы [22-25, 28-29]. Формирование этого типа аэрозоля обязано газовым пузырькам, находящимся на поверхности жидкой фазы. Известны различные механизмы генерации пузырей в жидкости - кавитация, разогрев жидкости, электрохимический процесс, генерация пузырей из капилляров и пор твердого тела, образование газообразных продуктов химических реакций, радиолиз воды.

Всплывший на поверхность жидкости пузырь живет довольно короткое время. Пленка купола пузыря утончается и разрывается, образуя значительное количество мелких пленочных капель размером от 0,1 до 4,3 мкм (рис. 1) [28]. Они разлетаются параллельно поверхности жидкости.

Из формирующейся полости пузыря происходит выброс кумулятивной струи, быстро теряющей устойчивость и дробящейся на капли (рис. 2) [28].

На рис. 3 приведен один из кадров ускоренной киносъемки процесса кумуляции [28].

После разрыва пузыря начинается движение поверхностных слоев жидкости к центру образовавшейся полости. При этом ускорение может достигать космиче- ских значений $-10^{6} g$, а начальная скорость выброса капель - 10 м/с [28]. При разрыве пузыря диаметром 1 мм максимальный размер кумулятивных капель составляет 100 мкм, пленочных - 1-20 мкм [33].

С помощью анализа размерности получено выражение начальной скорости выброса кумулятивной струи [28]:

$$
u=K \frac{E^{1 / 2}}{r^{3 / 2} \rho^{1 / 2}}\left(\frac{r^{2} \sigma}{E}\right)^{n}
$$

где $K$ - константа; $r$ - радиус пузыря; $\sigma$ - поверхностное натяжение; $E$ - энергия разрыва жидкости; $\rho$ - плотность жидкости.

Учет соотношения поверхностного натяжения и энергии разрыва жидкости выполнен с помощью безразмерного параметра $\frac{r^{2} \sigma}{E}$. Этот параметр оказывает заметное влияние на величину начальной скорости выброса кумулятивной струи.

Для расчета энергии разрыва жидкости аналогичным образом получено выражение [28]:

$$
E=A D^{2} v^{1 / 3} \rho\left(\frac{\eta}{D \rho}\right)^{m},
$$

где $A$ - коэффициент пропорциональности; $D$ - коэффициент диффузии; $v$ - мольный объем; $\rho$ - плотность жидкости; $\eta$ - вязкость; $m$ - показатель степени безразмерной величины $\frac{\eta}{D \rho}$. Установлено, что показатель степени $m$ должен принимать значение $m>2$ [28]. Очевидно, что гидродинамика образования кумулятивных капель тесным образом связана со структурой жидкости.

Важно сопоставить время формирования струи и релаксации поверхности. Время кумулятивной струи на порядок меньше времени достижения равновесных значений потенциала поверхности и поверхностного натяжения. Время релаксации для поверхностного потенциала составляет $0,4 \cdot 10^{-3} \mathrm{c}$, поверхностного натяжения $0,6 \cdot 10^{-3}$ с [11]. Поэтому можно утверждать, что процесс образования кумулятивной струи носит
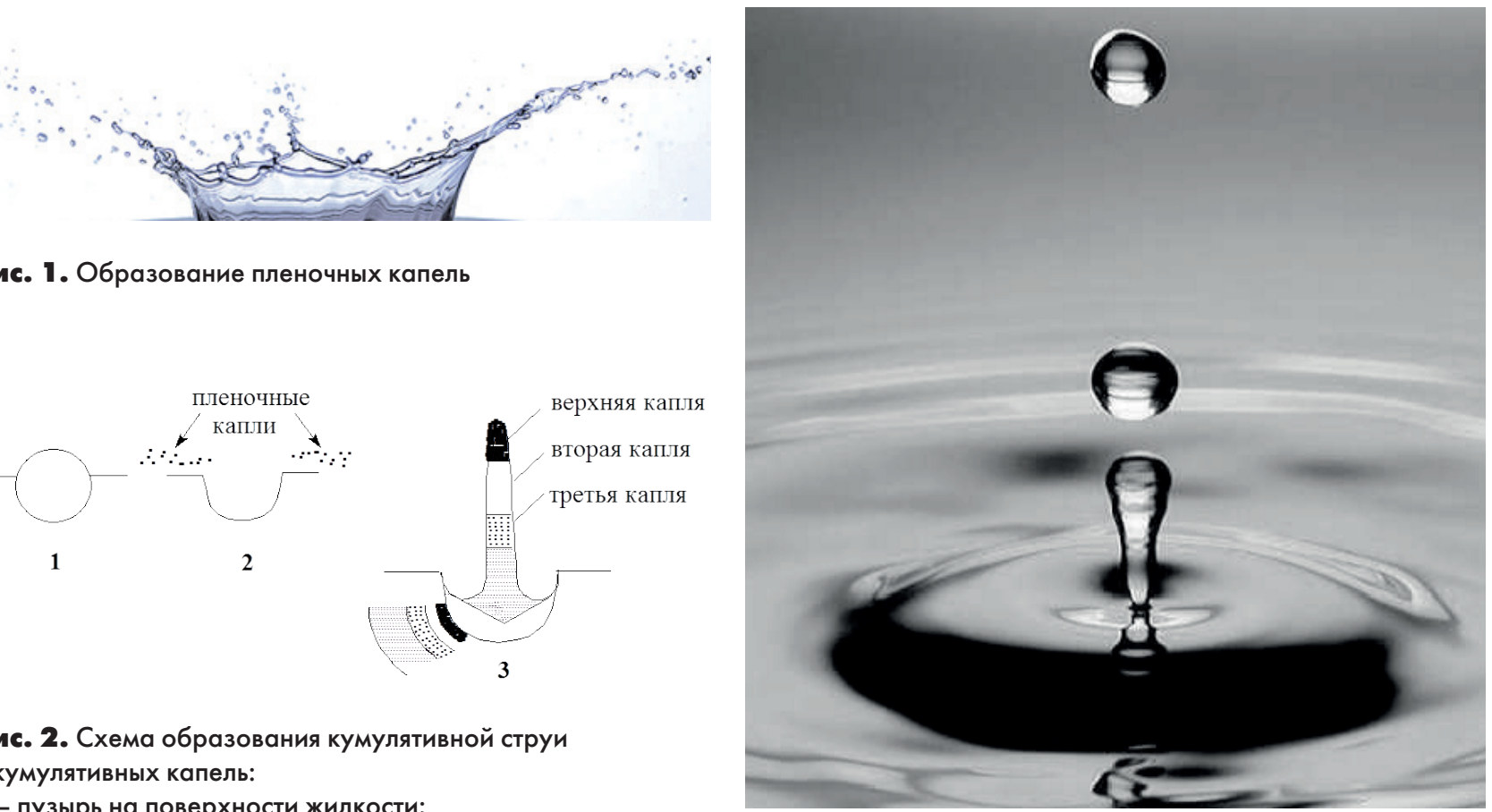

Pис. 2. Схема образования кумулятивной струи и кумулятивных капель:

1 - пузырь на поверхности жидкости;

2 - полость пузыря после его разрыва;

3 - образование капель из кумулятивной струи

верхняя капля

вторая капля

третья капля

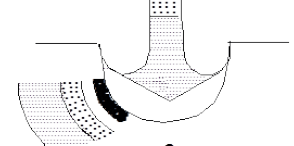

Рис. 3. Разрушение кумулятивной струи, образование кумулятивных капель 
нестационарный характер. Это обстоятельство является причиной фракционирования ионов растворов электролитов.

Кумулятивные капли всегда обогащались слабо гидратированными ионами, которые имеют тенденцию к вхождению в состав стационарного поверхностного слоя. Кумулятивные капли, размер которых существенно превышает размер пленочных капель, вносят основной вклад в процесс формирования морских аэрозолей, а после испарения воды - и ядер конденсации.

Важным моментом образования кумулятивных капель является тот факт, что в составе капель содержание анионов преобладало над содержанием катионов. Дисбаланс адсорбции ионов частично компенсировался подкислением капель для различной концентрации солевых систем. В табл. 3 приведены экспериментальные значения водородного показателя исходного раствора $\mathrm{pH}$, кумулятивных капель $\mathrm{pH}_{\mathrm{K}}$ и $\Delta \mathrm{pH}=\mathrm{pH}_{\mathrm{o}}-\mathrm{pH}_{\mathrm{\kappa}}$ [4].

Для вычисления значения $\Delta p H$ было получено выражение [4]:

$$
\begin{gathered}
\Delta \mathrm{pH}=\lg \left|1+\frac{4 \pi \gamma}{\varepsilon} \frac{t \delta^{2}}{D t-\delta^{2}-v t \delta}\right|, \\
\delta=\frac{v \varepsilon}{4 \pi \gamma}+\frac{D}{2 v_{\mathrm{o}}},
\end{gathered}
$$

где $\gamma$ - удельная электропроводность; $t$ - время; $\delta$ - толщина неравновесного поверхностного слоя при $t \rightarrow \infty$; $\varepsilon$ - диэлектрическая проницаемость; $D$ - коэффициент диффузии; $v$-скорость движения жидкости; $v_{\mathrm{o}}-$ начальная скорость.

Оценивая толщину пограничного слоя при $\gamma=10^{-7} c^{-1}$, $\varepsilon=100, v_{\mathrm{o}}=10 \mathrm{M} / \mathrm{c}$, получим $10^{-2} \mathrm{~cm}$. Эта величина совпадает с размером кумулятивных капель.

Расчет величины $\Delta \mathrm{pH}$ при $t \sim 10^{-2}-10^{-3} \mathrm{c}$, $D \sim 10^{-8}-10^{-7} \mathrm{~cm}^{2} / \mathrm{c}, \delta \sim 10^{-2}$ см дает значение в пределах $0,1-1,0$. Эти значения соответствуют данным, представленным в табл. 3.

Для оценки процесса фракционирования использовался безразмерный параметр - критерий разделения ионов:

$$
\Theta=\frac{\left(C_{i} / C_{j}\right)_{\mathrm{K}}}{\left(C_{i} / C_{j}\right)_{\mathrm{p}}},
$$

где $C_{i}$ и $C_{j}$ - концентрации слабо- и сильногидратированных ионов, индексы «к» и «р» относятся к каплям и исходному раствору соответственно.

Такие свойства ионов, как энергия гидратации, отрицательная поверхностная активность, коэффициент диффузии, оказывают заметное влияние на эффект разделения при образовании кумулятивных капель. Это подтверждается данными, представленными в табл. 4 [32].

Водно-солевая система $\mathrm{NaCl}-\mathrm{Na}_{2} \mathrm{SO}_{4}-\mathrm{H}_{2} \mathrm{O}$ с эквимолярной концентрацией солей 0,1 моль/л соответствует составу морской воды. В каплях содержание анионов хлора является преобладающим, что

\begin{tabular}{|c|c|c|c|c|c|c|c|}
\hline$C$ & $\mathrm{pH}_{0}$ & $\mathbf{p H}_{k}$ & $\Delta \mathrm{pH}$ & $C$ & $\mathbf{p H}_{0}$ & $\mathbf{p H}_{k}$ & $\Delta \mathrm{pH}$ \\
\hline \multicolumn{4}{|c|}{$\mathrm{LiCl}$} & \multicolumn{4}{|c|}{$\mathrm{NaBr}$} \\
\hline 0,1 & 4,66 & 4,41 & 0,25 & 0,1 & 4,90 & 4,42 & 0,48 \\
\hline 0,3 & 4,51 & 4,33 & 0,18 & 0,3 & 4,58 & 4,31 & 0,27 \\
\hline 0,5 & 4,23 & 4,08 & 0,15 & 0,5 & 4,37 & 4,21 & 0,16 \\
\hline 0,7 & 4,15 & 4,03 & 0,12 & 0,7 & 4,21 & 4,10 & 0,11 \\
\hline 1,0 & 4,09 & 3,97 & 0,12 & \multicolumn{4}{|c|}{$\mathrm{KBr}$} \\
\hline \multicolumn{4}{|c|}{$\mathrm{NaCl}$} & 0,1 & 4,53 & 4,29 & 0,24 \\
\hline 0,1 & 4,83 & 4,35 & 0,480 & 0,3 & 4,40 & 4,19 & 0,21 \\
\hline 0,3 & 4,58 & 4,09 & 0,49 & 0,5 & 4,30 & 4,09 & 0,21 \\
\hline 0,5 & 4,49 & 4,05 & 0,44 & \multicolumn{4}{|c|}{$\mathrm{NaF}$} \\
\hline 0,7 & 4,43 & 4,01 & 0,42 & 0,1 & 5,38 & 5,19 & 0,19 \\
\hline 1,0 & 4,21 & 3,96 & 0,25 & 0,4 & 5,28 & 5,11 & 0,17 \\
\hline \multicolumn{4}{|c|}{$\mathrm{KCl}$} & 0,7 & 5,21 & 4,98 & 0,23 \\
\hline 0,1 & 4,57 & 4,36 & 0,21 & 1,0 & 4,95 & 4,87 & 0,08 \\
\hline 0,3 & 4,48 & 4,22 & 0,26 & \multicolumn{4}{|c|}{ KI } \\
\hline 0,5 & 4,21 & 4,06 & 0,15 & 0,1 & 4,63 & 4,30 & 0,33 \\
\hline 0,7 & 4,17 & 3,96 & 0,21 & 0,4 & 4,42 & 4,23 & 0,19 \\
\hline 1,0 & 4,06 & 3,92 & 0,14 & 0,7 & 4,18 & 4,11 & 0,07 \\
\hline \multicolumn{4}{|c|}{$\mathrm{Na}_{2} \mathrm{SO}_{4}$} & 1,0 & 4,08 & 3,97 & 0,11 \\
\hline 0,1 & 4,69 & 4,34 & 0,35 & \multicolumn{4}{|c|}{$\mathrm{RbBr}$} \\
\hline 0,3 & 4,57 & 4,20 & 0,37 & 0,1 & 4,49 & 4,23 & 0,26 \\
\hline 0,6 & 4,37 & 4,10 & 0,27 & 0,5 & 4,43 & 4,16 & 0,27 \\
\hline 0,8 & 4,29 & 4,01 & 0,28 & 1,0 & 4,37 & 4,08 & 0,29 \\
\hline 1,0 & 4,19 & 3,94 & 0,25 & \multicolumn{4}{|c|}{$\mathrm{NaI}$} \\
\hline \multirow{3}{*}{-} & \multirow{3}{*}{-} & \multirow{3}{*}{-} & \multirow{3}{*}{-} & 0,1 & 5,39 & 5,23 & 0,16 \\
\hline & & & & 0,5 & 5,30 & 5,14 & 0,16 \\
\hline & & & & 1,0 & 5,08 & 4,98 & 0,09 \\
\hline
\end{tabular}
согласуется с составом морского аэрозоля $[12,17]$.

Значения $\mathrm{pH}_{\mathrm{o}}, \mathrm{pH}_{\kappa}, \Delta \mathrm{pH}$ в зависимости от концентрации $\boldsymbol{C}$ (моль/л) 
Критерий разделения ионов $(\Theta)$, энергия гидратации ионов $\left(\Delta G_{i}\right)$, поверхностная инактивность ионов $(\partial \sigma / \partial C)$,

коэффициенты диффузии $\left(D_{i}\right)$ при диаметре пор барботера 10 мкм,

концентрации солей 0,1 моль/л, температуре $25^{\circ} \mathrm{C}$,

глубине всплывания пузыря 5 см, высоте отбора капель 3 см

\begin{tabular}{|c|c|c|c|c|c|c|}
\hline \multirow{2}{*}{ Система } & \multicolumn{2}{|c|}{$\Theta$} & \multirow{2}{*}{$-\Delta \boldsymbol{G}_{i}$, ккал/моль } & \multirow{2}{*}{$\partial \sigma / \partial C$} & \multicolumn{2}{|c|}{$10^{5} \cdot D_{i}, \mathrm{cM}^{2} \cdot \mathrm{c}^{-1}$} \\
\hline & ионы & величина & & & $25^{\circ} \mathrm{C}$ & $18^{\circ} \mathrm{C}$ \\
\hline $\mathrm{NaCl}-\mathrm{Na}_{2} \mathrm{SO}_{4}-\mathrm{H}_{2} \mathrm{O}$ & $\mathrm{Cl}^{-} / \mathrm{SO}_{4}^{2-}$ & 2,60 & $79 / 249$ & - & $2,04 / 1,07$ & $1,71 / 0,89$ \\
\hline $\mathrm{NaCl}-\mathrm{Na}_{3} \mathrm{PO}_{4}-\mathrm{H}_{2} \mathrm{O}$ & $\mathrm{NO}_{3} / \mathrm{PO}_{4}^{3-}$ & 1,50 & $79 / 550$ & - & - & - \\
\hline $\mathrm{NaNO}_{3}-\mathrm{NaCl}-\mathrm{H}_{2} \mathrm{O}$ & $\mathrm{NO}_{3}{ }^{-} / \mathrm{Cl}^{-}$ & 2,30 & $69 / 79$ & $0,28 / 0,70$ & $1,91 / 2,04$ & $1,61 / 1,71$ \\
\hline $\mathrm{NaClO}_{4}-\mathrm{NaCl}-\mathrm{H}_{2} \mathrm{O}$ & $\mathrm{ClO}_{4}^{-} / \mathrm{Cl}^{-}$ & 2,40 & $50 / 72$ & - & $1,82 / 2,04$ & - \\
\hline $\mathrm{NaClO}_{4}-\mathrm{Na}_{2} \mathrm{SO}_{4}-\mathrm{H}_{2} \mathrm{O}$ & $\mathrm{ClO}_{4}^{-} / \mathrm{SO}_{4}^{2-}$ & 2,00 & $50 / 249$ & - & $1,82 / 1,07$ & - \\
\hline $\mathrm{NaBrO}_{3}-\mathrm{NaBr}-\mathrm{H}_{2} \mathrm{O}$ & $\mathrm{BrO}_{3}^{-} / \mathrm{Br}$ & 1,10 & - & - & - & - \\
\hline $\mathrm{KIO}_{3}-\mathrm{KI}-\mathrm{H}_{2} \mathrm{O}$ & $\mathrm{I}^{-} / \mathrm{IO}_{3}^{-}$ & 1,15 & - & - & - & $1,73 / 0,88$ \\
\hline $\mathrm{KI}-\mathrm{KCl}-\mathrm{H}_{2} \mathrm{O}$ & $\mathrm{I}^{-} / \mathrm{Cl}^{-}$ & 3,30 & $64 / 79$ & $0,15 / 0,70$ & $2,05 / 2,04$ & $1,73 / 1,71$ \\
\hline $\mathrm{KI}-\mathrm{KBr}-\mathrm{H}_{2} \mathrm{O}$ & $\mathrm{I}^{-} / \mathrm{Br}^{-}$ & 1,60 & $64 / 72$ & $0,18 / 0,64$ & $2,05 / 2,09$ & $1,73 / 1,75$ \\
\hline $\mathrm{KI}-\mathrm{K}_{2} \mathrm{SO}_{4}-\mathrm{H}_{2} \mathrm{O}$ & $\mathrm{I}^{-} / \mathrm{SO}_{4}^{2-}$ & 1,75 & $64 / 249$ & - & $2,05 / 2,07$ & $1,73 / 0,89$ \\
\hline $\mathrm{KCl}-\mathrm{LiCl}-\mathrm{H}_{2} \mathrm{O}$ & $\mathrm{K}^{+} / \mathrm{Li}^{+}$ & 1,40 & $79 / 121$ & $0,69 / 1,00$ & $1,96 / 1,03$ & $1,68 / 0,87$ \\
\hline $\mathrm{NaCl}-\mathrm{LiCl}-\mathrm{H}_{2} \mathrm{O}$ & $\mathrm{Na}^{+} / \mathrm{Li}^{+}$ & 1,35 & $97 / 121$ & $0,93 / 1,00$ & $1,34 / 1,03$ & $1,13 / 0,87$ \\
\hline $\mathrm{KCl}-\mathrm{NaCl}-\mathrm{H}_{2} \mathrm{O}$ & $\mathrm{K}^{+} / \mathrm{Na}^{+}$ & 1,10 & $79 / 97$ & $0,69 / 0,93$ & $1,96 / 1,34$ & $1,68 / 1,13$ \\
\hline $\mathrm{MnCl}_{2}-\mathrm{CuCl}_{2}-\mathrm{H}_{2} \mathrm{O}$ & $\mathrm{Mn}^{2+} / \mathrm{Cu}^{2+}$ & 1,10 & $433 / 499$ & - & $0,71 / 0,78$ & - \\
\hline $\mathrm{MgCl}_{2}-\mathrm{CuCl}_{2}-\mathrm{H}_{2} \mathrm{O}$ & $\mathrm{Mg}^{2+} / \mathrm{Cu}^{2}$ & 1,40 & $450 / 491$ & - & $0,71 / 0,78$ & $0,89 / 0,60$ \\
\hline $\mathrm{CuCl}_{2}-\mathrm{NiCl}_{2}-\mathrm{H}_{2} \mathrm{O}$ & $\mathrm{Cu}^{2+} / \mathrm{Ni}^{2+}$ & 1,00 & $491 / 491$ & - & $0,75 / 0,72$ & - \\
\hline $\mathrm{NaCl}-\mathrm{H}_{2} \mathrm{O}$ & $\mathrm{Cl}^{-} / \mathrm{Na}^{+}$ & 1,70 & $79 / 97$ & $0,70 / 0,93$ & $2,04 / 1,34$ & $1,71 / 1,13$ \\
\hline $\mathrm{NaBr}-\mathrm{H}_{2} \mathrm{O}$ & $\mathrm{Br} / \mathrm{Na}^{+}$ & 1,80 & $72 / 97$ & $0,64 / 0,93$ & $2,09 / 1,34$ & $1,75 / 1,34$ \\
\hline $\mathrm{NaI}-\mathrm{H}_{2} \mathrm{O}$ & $\mathrm{I}^{-} / \mathrm{Na}^{+}$ & 1,95 & $64 / 97$ & $0,15 / 0,93$ & $2,05 / 1,34$ & $1,73 / 1,34$ \\
\hline $\mathrm{KCl}-\mathrm{H}_{2} \mathrm{O}$ & $\mathrm{Cl}^{-} / \mathrm{K}^{+}$ & 1,45 & $79 / 79$ & $0,70 / 1,00$ & $2,04 / 1,96$ & $1,71 / 1,68$ \\
\hline $\mathrm{CuCl}_{2}-\mathrm{H}_{2} \mathrm{O}$ & $\mathrm{Cl}^{-} / \mathrm{Cu}^{2+}$ & 1,62 & $79 / 491$ & - & $2,04 / 0,78$ & $1,71 / 0,60$ \\
\hline $\mathrm{MgCl}_{2}-\mathrm{H}_{2} \mathrm{O}$ & $\mathrm{Cl}^{-} / \mathrm{Mg}^{2+}$ & 1,32 & $79 / 450$ & - & $2,04 / 0,71$ & $1,71 / 0,59$ \\
\hline $\mathrm{MnCl}_{2}-\mathrm{H}_{2} \mathrm{O}$ & $\mathrm{Cl}^{-} / \mathrm{Mn}^{2+}$ & 1,10 & $79 / 433$ & - & $2,04 / 0,71$ & - \\
\hline
\end{tabular}

С уменьшением диаметра пузыря эффект разделения ионов возрастает. На эффект разделения ионов оказывают влияние концентрация, глубина всплывания пузыря, частота генерации пузырей [28].

Для верхних капель (рис. 2) наблюдалось наибольшее разделение ионов. Это подтверждается результатами, приведенными на рис. 4 [28]. С увеличением высоты отбора кумулятивных капель растет вероятность улавливания верхних самых маленьких капель.

В каплях преобладают слабо гидратированные ионы, входящие в состав поверхностного слоя межфазной границы раствор электролита-газ, а также более подвижные ионы. Сказывается влияние коэффициента диффузии. Проявляется связь между критерием разделения и поверхностной инактивностью ионов. На основании этого предложены два механизма разделения ионов при образовании кумулятивных капель - «адсорбционный» и «диффузионно-кинетический» [28].

Процесс формирования капель носит динамический характер. Объяснить эффект разделения отрывом части стационарного двойного электрического слоя невозможно. Всплывание пузыря приводит к образованию в кормовой части вторичного, неравновесного двойного электрического слоя [7].

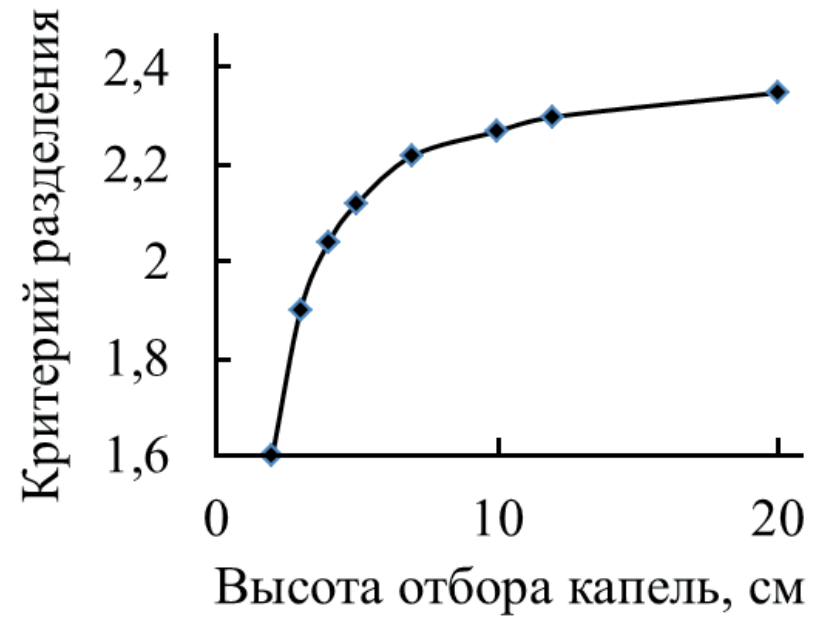

Pис. 4. Критерий разделения ионов $\mathrm{Cl}^{-}$и $\mathrm{SO}_{4}{ }^{2-}$ как функция высоты отбора капель

(Диаметр пузыря 1 мм, $25^{\circ} \mathrm{C}$, частота генерации - один пузырь в 2,5 с) 
Изменения структуры воды оказывают ощутимое влияние на эффект разделения. С упорядочиванием структуры воды разделение ионов усиливается. Это наблюдается при добавках спиртов, мочевины [31].

Особый интерес вызывает влияние низких температур, близких к температуре замерзания воды, на эффект разделения, поскольку талая вода обладает более упорядоченной структурой [26].

Водно-солевая система $\mathrm{NaCl}-\mathrm{Na}_{2} \mathrm{SO}_{4}-\mathrm{H}_{2} \mathrm{O}$ с эквимолярным содержанием солей (концентрация 0,1 мол/л) может рассматриваться в качестве модели морской воды. Эта система была приготовлена на конденсате, выдержанном двое суток (I), и на талой воде (II). Использовался также талый раствор (III), то есть водно-солевая система предварительно замораживалась, а затем оттаивала. В табл. 5 приведены критерии разделения анионов $\mathrm{Cl}^{-} / \mathrm{SO}_{4}^{2-}$ для трех систем (I-III), а также время жизни свободных жидких пленок. Время жизни свободных жидких пленок может рассматриваться в качестве фактора стабилизации структуры воды [26]. Упорядочивание структуры воды приводит к увеличению времени жизни пленок.

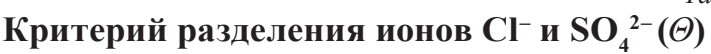
и время жизни пленок $\tau$ [5]

\begin{tabular}{|c|c|c|}
\hline Система (см. текст) & $\boldsymbol{\Theta}$ & $\boldsymbol{\tau}, \boldsymbol{c}$ \\
\hline I & 2,0 & 0,15 \\
\hline II & 2,4 & 0,60 \\
\hline III & 2,2 & 0,40 \\
\hline
\end{tabular}

Самый сильный эффект разделения наблюдается для растворов с упорядоченной структурой воды, то есть растворов, приготовленных на талой воде. Это соответствует обогащению поверхностного слоя анионами $\mathrm{Cl}^{-}$.

Поверхностные воды в той или иной степени содержат поверхностно-активные вещества (ПАВ). В этом случае эффект разделения ионов нивелируется. Ионы вытесняются молекулами ПАВ из поверхностного слоя. Этому в основном подвержены анионы, входящие в плотную часть стационарного двойного электрического слоя межфазной границы раствор электролита-газ. Этот эффект иллюстрирует рис. 5 [28].

С кумулятивными каплями с водной поверхности удаляются углеводородные пленки [18]. Пленка углеводорода утончается до толщины, соизмеримой с длиной волны видимого света, до появления интерференции. После этого пленка теряет свою устойчивость, распадаясь на отдельные линзы. Время полного удаления углеводорода соответствует удалению отдельных линз. В табл. 6 приведены все стадии удаления углеводородной пленки, показано влияние природы углеводорода, подложки и толщины пленки $H$ на ее удаление. Конечно, с кумулятивными каплями могут удаляться пленки и других не растворимых в воде жидкостей.

С кумулятивными каплями удаляются коллоидные частицы и частицы суспензий [28]. При удалении частиц коллоидной серы с кумулятивными каплями золь становится оптически прозрачным. Рис. 6 демонстрирует уменьшение концентрации серы в исходной жидкости в функции времени при удалении кумулятивных капель.

В присутствии электролита процесс удаления дисперсных частиц с кумулятивными каплями усиливается. Это можно наблюдать при введении хлорида калия в полистирольный латекс (размер частиц 0,79 мкм) [30]. В табл. 7 показано влияние ионной силы при введении в дисперсионную среду полистирольного латекса хлорида калия на увеличение содержания частиц в каплях.

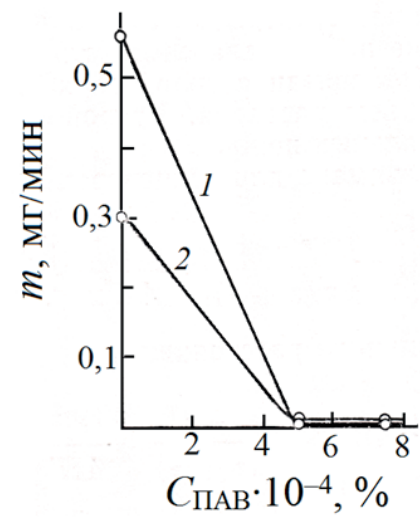

Рис. 5. Влияние концентрации ПАВ (ОП-10) на содержание ионов в кумулятивных каплях

(Анионы: $1-\mathrm{Cl}^{-}, 2-\mathrm{SO}_{4}{ }^{2-}$. Концентрация солей -

0,1 моль/л)

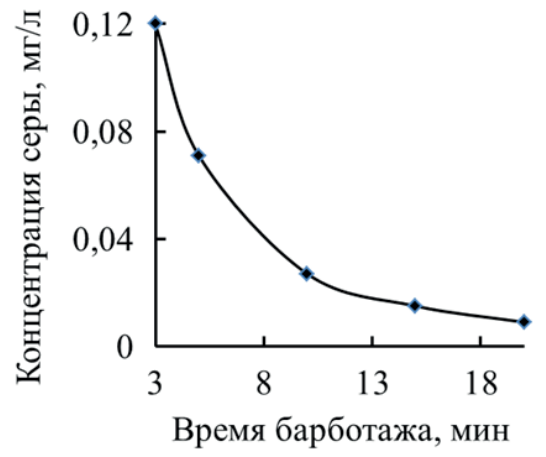

Рис. 6. Изменение концентрации серы в исходной жидкости во времени при удалении кумулятивных капель

Время появления интерференции $\left(\tau_{\text {интер }}\right)$, появления линз $\left(\tau_{\text {линз }}\right)$, полного удаления углеводорода $\left(\tau_{\text {пул }}\right)$

\begin{tabular}{|c|c|c|c|c|c|}
\hline \multirow{2}{*}{ Подложка } & \multirow{2}{*}{ Углеводород } & \multirow{2}{*}{$\underset{\text { мкм }}{H,}$} & \multicolumn{3}{|c|}{ Время, мин } \\
\hline & & & $\tau_{\text {интер }}$ & $\tau_{\text {линз }}$ & $\tau_{\mathrm{ny}}$ \\
\hline \multirow{4}{*}{ Водная } & $H$-декан & 21,5 & 5,6 & 5,8 & 6,8 \\
\hline & H-ундекан & 21,5 & 14,0 & 15,0 & 20,0 \\
\hline & н-додекан & 21,5 & 75,0 & 90,0 & 110,0 \\
\hline & t-ундекан & 4,5 & 3,0 & 3,5 & 5,0 \\
\hline $\begin{array}{c}\text { Водно-солевая система } \\
\mathrm{NaCl}-\mathrm{Na}_{2} \mathrm{SO}_{4}-\mathrm{H}_{2} \mathrm{O}\end{array}$ & н-ундекан & 4,5 & 6,0 & 6,5 & 7,5 \\
\hline
\end{tabular}


Табл. 7

Ионная сила $(I)$ и концентрация частиц латекса

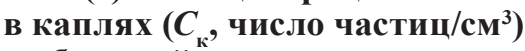
при объемной концентрации частиц $\left(C_{0}\right.$, число частиц $\left./ \mathrm{cm}^{3}\right)$, равной $3,5 \cdot 10^{7}$

\begin{tabular}{|c|c|c|}
\hline$I$ & $C$, число частиц/см${ }^{3}$ & $C_{\sigma} / C_{0}$ \\
\hline $10^{-5}$ & $<5 \cdot 10^{6}$ & $<0,15$ \\
\hline $10^{-4}$ & $<2 \cdot 10^{7}$ & $<0,60$ \\
\hline $10^{-3}$ & $4,5 \cdot 10^{7}$ & 1,30 \\
\hline $2,5 \cdot 10^{-3}$ & $7,5 \cdot 10^{7}$ & 2,10 \\
\hline $10^{-2}$ & $2,0 \cdot 10^{8}$ & 5,70 \\
\hline $10^{-1}$ & $1,7 \cdot 10^{8}$ & 4,90 \\
\hline
\end{tabular}

С кумулятивными каплями легко переносятся микроорганизмы, причем содержание микроорганизмов в каплях возрастает с увеличением глубины всплывания пузыря. В табл. 8 показано изменение соотношения содержания микроорганизмов (музейный штамм чудесной палочки Serratia marcescens) в каплях $\left(C_{\mathrm{K}}\right)$ и исходной жидкости $\left(C_{\mathrm{o}}\right)$ с изменением глубины всплывания пузыря $(l)$ [28].

Связь между глубиной всплывания $l$ Табл. 8 и соотношением концентраций $C_{\mathrm{\kappa}} / C_{0}$ Serratia marcescens

\begin{tabular}{|c|c|c|c|c|}
\hline$l, \mathrm{~cm}$ & 1 & 5 & 10 & 15 \\
\hline$C_{\mathrm{\kappa}} / C_{\mathrm{o}}$ & 2,5 & 12 & 13 & 16 \\
\hline
\end{tabular}

Наиболее интересной проблемой кумуляции жидкости при образовании кумулятивных капель является дисбаланс адсорбции ионов, который характерен для стационарного двойного электрического слоя границы раздела раствор электролита-газ. Причина этого лежит в нестационарном характере процесса кумуляции жидкости. Первоначально происходит скольжение слоя более тонкого, чем слой с повышенной вязкостью. Толщина этого слоя составляет $10 \%$ от толщины стационарного поверхностного слоя [28]. Определенный вклад в дисбаланс адсорбции вносит конвективная диффузия ионов в кормовой части пузыря [7]. В кормовой части всплывающего пузыря образуется достаточно протяженный вторичный двойной электрический слой, размер которого достигает десятков микрометров. Таким образом, разделение ионов происходит не в стационарном, а в динамическом вторичном двойном электрическом слое.

Дисбаланс адсорбции анионов и катионов в кумулятивных каплях становится возможным, если допустить, что ионы в процессе кумуляции сбрасывают часть избыточного заряда [2].

С использованием метода «зеркальных изображений» может быть вычислена величина эффективного заряда иона:

$$
\begin{aligned}
& Z_{i}=\sqrt{\frac{T x}{a} \ln \left\langle 1-\frac{\Gamma_{a}}{\Gamma_{\mathrm{o}}}\left(1-\exp \left[-\frac{a Z_{\mathrm{o}}^{2}}{T x}\right]\right)\right\rangle}, \\
& a=\frac{e^{2}(\varepsilon-1)}{4 \pi k \varepsilon_{0} \varepsilon(\varepsilon+1)},
\end{aligned}
$$

где $e$ - величина элементарного заряда иона; $\varepsilon-$ диэлектрическая проницаемость растворителя; $\Gamma_{a}$ и $\Gamma_{o}-$ адсорбция электролита в жидкости барботажного аэрозоля и объемной фазы соответственно; $Z_{o}$ - заряд иона в объемном растворе.
На этой основе была рассчитана потеря части электронной плотности иона $(\Delta e / e)$. Потеря электронной плотности должна происходить на расстоянии $5 \AA$ от межфазной границы (рис. 7).

В связи с зафиксированным дисбалансом зарядов в кумулятивной капле (содержание анионов превышает содержание катионов, а экспериментально определенные изменения $\mathrm{pH}$ все-таки недостаточны для полной компенсации избыточного отрицательного заряда) необходимо рассмотреть вопрос об их взаимной экранировке.

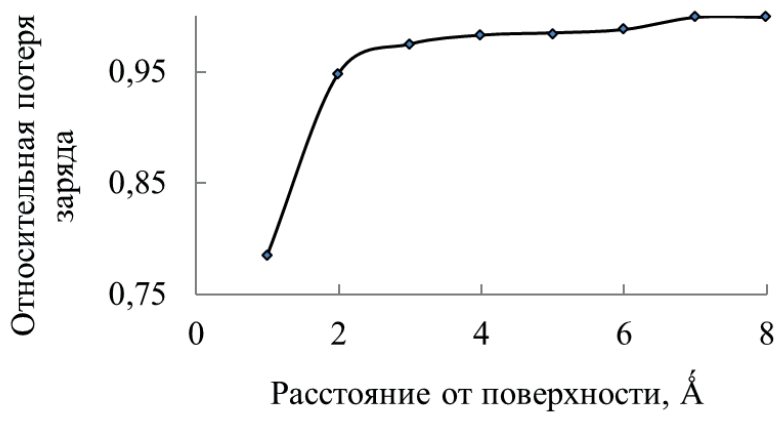

Рис. 7. Зависимость относительной потери заряда от расстояния до межфазной границы (система NaF- $\mathrm{H}_{2} \mathrm{O}$, концентрация 0,2 моль/л)

При рассмотрении вопроса о формировании заряда капли необходимо в теории Дебая-Хюккеля учитывать дисбаланс электрических зарядов. Для этого в основополагающем уравнении:

$$
\nabla^{2} \psi=-\frac{4 \pi e}{\varepsilon} \sum_{i=1}^{N} z_{i} n_{i}^{0} \exp \left[-\frac{e z_{i}}{R T} \psi\right]
$$

(где $e$ - величина элементарного заряда; $\varepsilon$ - диэлектрическая проницаемость; $z_{i}$ - валентность иона сорта $i$; $n_{i}^{0}$ - общее число зарядов сорта $i$ в единице объема раствора; $N$ - величина, определяющая степень дисбаланса электрических зарядов; $\psi$ - потенциал ионной атмосферы) выполним процедуру разложения экспоненты в ряд с сохранением двух первых членов разложения [28]:

$$
\exp \left[-\frac{e z_{i}}{R T} \psi\right]=1-\frac{e z_{i}}{R T} \psi .
$$

Для характеристики ионной атмосферы ж введем новые обозначения:

$$
\mathcal{\varkappa}^{2}=\frac{4 \pi}{\varepsilon} \cdot \frac{e^{2}}{R T} \cdot \sum z_{i}^{2} n_{i}^{0}, N=-\frac{4 \pi e}{\varepsilon} \sum z_{i} n_{i}^{0} .
$$

При $N=0$ (электрически нейтральная система) получим:

$$
\nabla^{2} \psi=\mathcal{\varkappa}^{2} \psi+N
$$

Базируясь на сферической симметрии ионной атмосферы, получим неоднородное дифференциальное уравнение:

$$
\frac{1}{r^{2}} \cdot \frac{\partial}{\partial r}\left(r^{2} \frac{\partial \psi}{\partial r}\right)=\varkappa^{2} \psi+N
$$

Очевидно, что неоднородность приведенного уравнения связана со степенью дисбаланса ионов. Ряд преобразований позволил найти решение в виде [3]:

$$
\psi=C_{1} \exp [-\varkappa r] r^{-1}+C_{2} \exp [\varkappa r] r-\frac{N}{\varkappa^{2}},
$$

где $C_{1}$ и $C_{2}-$ постоянные интегрирования. 
Учитывая, что $C_{2}=0$, поскольку $r \rightarrow \infty, \psi \rightarrow 0$ (следствие физического смысла потенциала), получим:

$$
\psi=C_{1} \exp [-\varkappa r] r^{-1}-\frac{N}{\varkappa^{2}} .
$$

Для точечного заряда, допуская, что потенциал иона стремится к собственному потенциалу, запишем:

$$
\psi_{r \rightarrow 0}=\psi_{i}=\frac{e z_{i}}{\varepsilon r}>\frac{N}{\varkappa^{2}} .
$$

При этом важно соблюсти неравенство:

$$
r<\frac{4 \pi e^{2} z_{i} \sum z_{i}^{2} n_{i}^{0}}{\varepsilon R T \sum z_{i} n_{i}^{0}} \approx 10^{-6} \mathrm{cM} .
$$

Тогда при $C_{1}=e z_{i} / \varepsilon$ получим:

$$
\psi=\frac{e}{\varepsilon}\left\{z_{i} \exp [-\varkappa r] r^{-1}+\frac{4 \pi}{\varkappa^{2}} \sum z_{i} n_{i}^{0}\right\} .
$$

Второй член уравнения важен при учете дисбаланса заряда. Потенциал поля в условиях дисбаланса анионов и катионов в капле ослабляется на величину диэлектрической проницаемости, но и, самое важное, на величину $\varkappa^{2}$.

Для электронейтральной системы второй член уравнения равен нулю. В итоге получим:

$$
\psi=\frac{e z_{i}}{\varepsilon r} \exp [-\varkappa r]
$$

На расстоянии, при котором энергия пробного заряда будет равна тепловой энергии, действием поля можно будет пренебречь:

$$
e z_{i} \psi=R T \text {. }
$$

В этом случае можно получить выражение для потенциала ионной атмосферы:

$$
\frac{\exp [-\varkappa r]}{r}=\frac{e R T}{e^{2} z_{i}^{2}}-\frac{4 \pi e}{\varkappa^{2} z_{i}} \sum z_{i} n_{i}^{0} .
$$

Воспользовавшись приближением:

$$
\exp [-\varkappa r] \approx 1-\varkappa r,
$$

найдем радиус полной экранировки заряда [3]:

$$
\delta=\frac{1}{\varkappa+\frac{\varepsilon}{e^{2} z_{i}}\left[R T-\frac{4 \pi e^{2} z_{i}}{\varepsilon} \sum \frac{z_{i} n_{i}^{0}}{\varkappa^{2}}\right]} .
$$

Расстояние $\delta$ соответствует толщине поверхностного слоя межфазной границы жидкость-газ.

Расчет заряда капли по ее ионному составу базируется на идее, что электрическое поле капли создают только те ионы, которые расположены в поверхностном слое толщиной $\delta$. Остальные заряды, расположенные в объеме капли, экранируются. Все это позволило получить выражение для заряда капли [3]:

$$
Q=\frac{4 \pi e R_{\mathrm{K}}^{2} \sum z_{i} n_{i}^{0}}{\varkappa+\frac{\varepsilon}{\mathrm{e}^{2} \mathrm{z}_{\mathrm{i}}}\left[R T-\frac{4 \pi e^{2} z_{i}}{\varepsilon \varkappa^{2}} \sum z_{i} n_{i}^{0}\right]},
$$

где $R_{\text {к }}$ радиус сферической капли.

В табл. 9 приведены расчетные значения концентрации ионов для системы $\mathrm{NaCl}-\mathrm{Na}_{2} \mathrm{SO}_{4}-\mathrm{H}_{2} \mathrm{O}$ с эквимолярными концентрациями солей 0,1 моль/л [3]. В этом случае величина заряда капли радиусом $1,1 \cdot 10^{-2}$ см составила $7,8 \cdot 10^{-16}$ Кл.

Табл. 9

Концентрация ионов в кумулятивной капле $n_{i}$

\begin{tabular}{|c|c|c|c|}
\hline Ионы & $\mathbf{C l}^{-}$ & & $\mathbf{N a}^{+}$ \\
\hline$n_{i} \cdot 10^{20} \mathrm{~cm}^{-3}$ & 2,904 & 1,711 & 0,989 \\
\hline
\end{tabular}

Строгий расчет заряда капли возможен при учете дифференциального характера распределения ионов вблизи межфазной границы. С учетом этого получено выражение для распределения потенциала:

$$
\varphi=\varphi_{0} \exp [-\varkappa x]+\frac{1}{2} \cdot \frac{\Delta n}{n_{\infty}} \cdot \frac{R T}{e z} .
$$

При балансе ионов $(\Delta n=0)$ и $x \rightarrow \infty$ имеем:

$$
\varphi_{\infty}=-\frac{1}{2} \cdot \frac{\Delta n}{n_{\infty}} \cdot \frac{R T}{e z}
$$

Для системы $\mathrm{NaCl}-\mathrm{H}_{2} \mathrm{O}$ (концентрация 0,1 моль/л; $n^{+}=1,45 \cdot 10^{20} \mathrm{~cm}^{-3}$ и $\left.n^{-}=2,89 \cdot 10^{20} \mathrm{~cm}^{-3}\right) \varphi_{\infty}=0,043$ В. Для однозарядного иона энергия в этом поле будет равна $6,9 \cdot 10^{-21}$ Дж. С учетом энергии водородной связи 5 ккал/моль $\left(35 \cdot 10^{-21}\right.$ Дж) можно прийти к выводу о механической устойчивости такой капли.

И все-таки, если обратить внимание на дисбаланс анионов и катионов в кумулятивных каплях, следует ожидать проявления особых физических свойств жидкости капель.

В этой связи надо отметить специфику испарения кумулятивных капель. На определенном этапе испарения капля взрывается, сбрасывая избыточный заряд и массу [21].

Экспериментально было установлено изменение поверхностного натяжения жидкости капель $\left(\sigma_{\kappa}\right)$ по сравнению с исходной жидкостью $\left(\sigma_{o}\right)$.

Рис. 8 демонстрирует зависимость отношения поверхностного натяжения жидкости кумулятивных капель и объемной фазы от энергии гидратации ионов [28].

Значение отрицательной адсорбции объемной жидкости всегда было выше, чем жидкости кумулятивных капель [20]. Поверхностный слой жидкости кумулятивных капель был обогащен электролитом в большей степени, чем объемный. На основании этого можно допустить, что при кумуляции происходит дегидратация ионов. Это хорошо согласуется с перераспределением электронной плотности. Ионы жидкости кумулятивных капель теряют часть избыточного заряда, который распределяется по всей массе жидкости. В этом случае нужно говорить об образовании гидратированного электрона и свободных молекул, например хлора:

$$
2 \mathrm{Cl}^{-} \rightarrow 2 e_{a q}^{-}+\mathrm{Cl}_{2}
$$

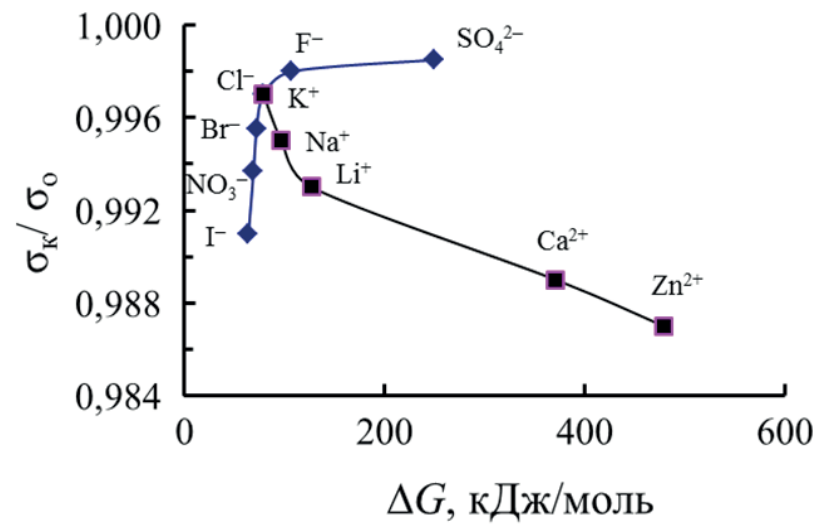

Рис. 8. Изменение отношения поверхностного натяжения жидкости кумулятивных капель и объемной фазы $\sigma_{k} / \sigma$ от энергии гидратации ионов $\Delta G$ 
Аналогичным образом может быть образован свободный бром и йод. В реальных условиях в воздухе над морем зафиксировано появление свободных галогенов $[1,17]$.

Изменение физических свойств жидкости кумулятивных капель ярко проявляется в изменении краевого угла смачивания поверхности твердого тела $[15$, 19]. В табл. 10 приведены краевые углы смачивания поверхности фторопласта кумулятивными каплями $\theta_{\kappa}$ и объемной жидкостью $\theta_{\text {o }}$.

Краевые углы смачивания фторопласта кумулятивными каплями $\theta$ и объемной жидкости $\theta_{0}$

\begin{tabular}{|c|c|c|}
\hline Концентрация NaCl, моль/л & $\boldsymbol{\theta}_{\text {к }}$ & $\boldsymbol{\theta}_{\text {о }}$ \\
\hline 0,1 & $127^{\circ}$ & $136^{\circ}$ \\
\hline 0,5 & $129^{\circ}$ & $139^{\circ}$ \\
\hline 1,0 & $133^{\circ}$ & $144^{\circ}$ \\
\hline
\end{tabular}

Улучшение смачивания пылевых частиц кумулятивными каплями было использовано для улучшения процесса гидрообеспыливания [5].

Проблема химического взаимодействия океанатмосфера остается одной из важнейших глобальных проблем современности. Особый интерес вызывает появление свободных галогенов над морем.

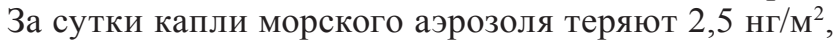

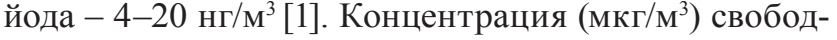
ных галогенов в атмосфере над морем лежит в пределах: 0,1-1,0 - для хлора, 0,005-0,05 - для брома, 0,01-0,06 - для йода [1]. Выше было показано, что происхождение свободного хлора связано с дисбалансом адсорбции анионов, сбросом избыточного заряда и появлением гидратированных электронов.

Можно привести и другой механизм появления свободных галогенов в атмосфере над морем [27]. Появление гидратированных электронов в морской воде может происходить в результате радиоактивного распада изотопа $K^{40}$ при воздействии космического и ультрафиолетового излучения.

В морской воде одной из форм, в которой встречается йод, является анион $\mathrm{IO}_{3}^{-}$. Сведения о содержании $\mathrm{BrO}_{3}{ }^{-}$в морской воде отсутствуют. Известно взаимодействие аниона $\mathrm{BrO}_{3}^{-}$с гидратированным электроном [16]:

$$
\mathrm{BrO}_{3}{ }^{-}+e_{a q}^{-} \rightarrow \mathrm{BrO}_{3}^{2-} \rightarrow \mathrm{BrO}_{2}+\mathrm{O}_{2}^{2-} .
$$

Следует отметить, что реакционная способность у аниона $\mathrm{IO}_{3}^{-}$выше, чем у аниона $\mathrm{BrO}_{3}^{-}$. Поэтому подобное взаимодействие для аниона $\mathrm{IO}_{3}^{-}$также возможно. При подкислении возможна реакция [16]:

$$
\mathrm{I}^{-}+\left(\mathrm{BrO}_{2}\right)_{a q} \rightarrow \mathrm{I}+\mathrm{BrO}_{2}^{-} .
$$

В кислом растворе анион $\mathrm{BrO}_{3}{ }^{2-}$ окисляет анионы $\mathrm{Br}^{-}$и $\mathrm{I}^{-}$, например [16]:

$$
\begin{gathered}
\mathrm{I}^{-}+\mathrm{BrO}_{3}^{2-} \rightarrow \mathrm{I}+\mathrm{BrO}_{2}^{-}, \\
\mathrm{Br}^{-}+\mathrm{BrO}_{3}^{2-} \rightarrow \mathrm{Br}+\mathrm{BrO}_{2}^{-} .
\end{gathered}
$$

$\mathrm{O}$ подкислении кумулятивных капель $(\Delta \mathrm{pH}=$ 0,1-1,0) говорилось выше. Эксперимент дает величину $\Delta \mathrm{pH}$ порядка 0,5 .

В табл. 11 приведены константы скорости реакции $e_{a q}^{-}$и значения $\mathrm{pH}$ для взаимодействия $e_{a q}^{-}$с неорганическими анионами [16]. Все эти реакции возможны.

Табл. 11

Константы скорости $\boldsymbol{k}$ и значения рН для взаимодействия $e_{a q}^{-}$с неорганическими анионами

\begin{tabular}{|c|c|c|}
\hline Реагент & $\mathbf{p H}$ & $\boldsymbol{k}$, моль $^{-\mathbf{1}} \cdot \mathbf{c}^{\mathbf{- 1}}$ \\
\hline $\mathrm{BrO}_{3}^{-}$ & 7 & $2,1 \cdot 10^{9}$ \\
\hline $\mathrm{Cl}^{-}$ & $7-12$ & $<1 \cdot 10^{4}$ \\
\hline $\mathrm{IO}_{3}^{-}$ & 7 & $7,7 \cdot 10^{9}$ \\
\hline $\mathrm{I}_{3}^{-}$ & 7 & $2 \cdot 10^{10}$ \\
\hline
\end{tabular}

Образование свободного йода может также происходить под действием квантов света по схеме [9]:

$$
2 \mathrm{I}^{-}+1 / 2 \mathrm{O}_{2}+2 \mathrm{H}^{+} \stackrel{h v}{\rightarrow} \mathrm{I}_{2}+\mathrm{H}_{2} \mathrm{O} .
$$

В завершение сказанного отметим, что дисбаланс адсорбции анионов и катионов при кумуляции нашел подтверждение $[13,14]$. Были рассчитаны и определены экспериментально энергии активации выхода ионов из раствора хлорида натрия. Для $\mathrm{Cl}^{-}$и $\mathrm{Na}^{+}$эти величины оказались равными 21 и 37 ккал/моль соответственно.

\section{Литература}

1. Безбородов А.А., Еремеев В.Н. Физикохимические аспекты взаимодействия океана и атмосферы. - Киев : Наукова думка, 1984. - 192 с.

2. Власов Ю.В., Гасанов В.М., Хентов В.Я., Виленский В.М. Изучение поверхностного натяжения жидкости барботажного аэрозоля // Вестник Ростовского государственного ун-та путей сообщения. - 2003. - № 1. - С. 114-117.

3. Власов Ю.В. О заряде капель, образующихся при разрыве газовых пузырей на границе раствор электролита-газ // Математические методы в физике, технике и экономике. - Но- вочеркасск : Известия вузов. Электромеханика, 2006. - С. 40-48.

4. Власов Ю.В., Хентов В.Я., Гапонова Т.В., Гасанов В.М. Изучение динамики формирования электрического заряда при капельном уносе // Журн. физ. химии. - 1984. - № 10. C. $2550-2554$.

5. Гасанов В.M. Совершенствование процессов снижения концентрации вредных веществ в воздухе рабочей зоны при гальванической обработке металлических элементов на предприятиях стройиндустрии. - Автореф. ... дисс. 
канд. техн. наук. - Ростов н/Д : Ростовский государственный строительный университет, 2003.

6. Гинзбург А.С., Губанова Д.П., Минашкин B.M. Влияние естественных и антропогенных аэрозолей на глобальный и региональный климат // Рос. хим. журн. - 2008. T. LII. - № 5.- C. 112-119.

7. Духин C.C. Разделение ионов вторичного двойного слоя при разрыве пузырей на границе раздела раствор электролита-газ // Коллоидный журн. - 1974. - № 3. - С. 547-548.

8. Ивлев Л.С., Довгалюк Ю.А. Физика атмосферных аэрозольных систем. - СПб. : НИИХ СПбГУ, 1999. - 194 с.

9. Ивлев Л.С. Химический состав и структура атмосферных аэрозолей. - Л. : Изд-во ЛГУ, 1982. -368 c.

10. Кондратьев К.Я., Москаленко Н.И., Поздняков Д.В. Атмосферный аэрозоль. - Л. : Гидрометеоиздат, 1983. - $224 \mathrm{c.}$

11. Кочурова Н.Н., Русанов А.И. Поверхностные свойства воды с неравновесной структурой поверхности // Поверхностные силы в тонких пленках. - М. : Наука, 1979. - С. 224-227.

12. Савенко В.С. Химия водного поверхностного микрослоя. - Л. : Гидрометеоиздат, 1990. - 184 с.

13. Савченко А.В., Свиркунов П.Н., Смирнов B.В. Эмиссия ионов при лазерном нагреве капель электролитов // Квантовая электроника. - 1977. - Т. 4. - № 10. - С. 2182-2188.

14. Савченко А.В., Свиркунов П.Н., Смирнов В.В. Испарительный перенос ионов примесей из растворов в воздух // Проблемы метеорологии. - Л. : Гидрометеоиздат, 1979. C. $115-125$.

15. Соколова Г.Н., Хентов В.Я., Власов Ю.В. Смачивание поверхностей твердых тел барботажным аэрозолем // Изв. вузов. Химия и хим. технол. - 1987. - Т. 30. - № 5. - С. 120-121.

16. Харт Э., Анбар М. Гидратированный электрон. - М. : Атомиздат, 1973. - 280 с.

17. Хорн Р. Морская химия. - М. : Мир,1972. $399 \mathrm{c}$.

18. Хентов В.Я., Виленский В.М., Тамазова Н.В. Перенос углеводородных пленок с поверхности воды в капли, образующиеся при разрыве газовых пузырей // Вестник Ростовского государственного ун-та путей сообщения. - 2002. - № 2. - С. 150-152.

19. Хентов В.Я., Гасанов В.М., Власов Ю.В. Смачивание поверхности твердого тела каплями жидкости, образовавшимися при разрушении газовых пузырей // Известия СевероКавказского научного центра высшей школы. Естественные науки. - 1988. - № 1. - С. 64-65.

20. Хентов В.Я., Гасанов В.М., Власов Ю.В. Дегидратация ионов при кумуляции в микро- слоях жидкости // Инженерно-физический журн. - 2014. - Т. 87. - № 2. - С. 347-350.

21. Хентов В.Я., Гасанов В.М., Власов Ю.В., Халилов Я.Х. Об испарении капель барботажного аэрозоля с твердой подложки // Инженерно-физический журн. - 1988. - Т. 55. - № 6. С. 894-896.

22. Хентов В.Я., Гаршин В.В., Семин Е.Г., Остриков Н.М., Башкиров М.М. Исследование потенциалов течения в процессе утончения свободных жидких пленок // Тезисы докладов IV Всесоюзного совещания по поверхностным силам. - М. : АН СССР, 1969. - С. 56-57.

23. Хентов В.Я., Крыжановская В.В., Семин Е.Г. О разделении ионов и при капельном уносе // Журн. прикладной химии. - 1971. № 6. - С. 1413-1414.

24. Хентов В.Я., Крыжановская В.В., Семин Е.Г. О влиянии ПАВ на разделение ионов и при капельном уносе // Журн. прикладной химии. - 1971. - № 11. - С. 2550-2551.

25. Хентов В.Я., Крыжановская В.В., Семин Е.Г. Метод разделения ионов // Изв. ВУЗов СССР. Химия и химические технологии. 1972. - T. 15. - C. 481-483.

26. Хентов В.Я., Никиташ В.Г., Васильева В.В., Власов Ю.В. О времени жизни двусторонних пленок талой воды // Коллоидный журн. - 1972. - № 5. - С. 811.

27. Хентов В.Я., Регнер М.В., Гаршин В.И., Гасанов В.М. О содержании свободных хлора, брома и йода в атмосфере над морем // Безопасность жизнедеятельности. Охрана труда и окружающей среды. Межвуз. сб. науч. трудов. - Ростов н/Д : Рост. гос. акад. с.-х. машиностроения, 2006. - Вып. 10. - С. 33-36.

28. Хентов В.Я., Семин Е.Г., Власов Ю.В., Гасанов B.M. Барботаж. Барботажный аэрозоль. Проблемы и решения. - СПб. : Химиздат, 2013. - 168 c.

29. Хентов В.Я., Семин Е.Г. Высота взлета капель как структурно чувствительная характеристика растворов // Журн. физ. химии. 1971. - № 7. - С. 1243-1246.

30. Хентов В.Я. Физикохимия капельного уноса. - Ростов н/Д : Изд-во Ростовского гос. ун-та, 1979. - $128 \mathrm{c}$.

31. Хентов В.Я., Шадрин Г.Н., Хрипун М.К., Воронович А.Н. Влияние добавок неэлектролитов на состав неравновесного поверхностного слоя в системе $\mathrm{NaCl}-\mathrm{Na}_{2} \mathrm{SO}_{4}-\mathrm{H}_{2} \mathrm{O} / /$ Коллоидный журн. -1980 . - № 1. - С. 166-170.

32. Хентов В.Я., Шакирова Ф.А. Влияние физикохимических свойств ионов на разделение при капельном уносе // Журн. физ. химии. 1978. - № 5. - C. 1241-1244.

33. Woodcock A.H. Salt nuclei in marine air as a function of altitude and wind force // J. Meteorol. 1953. - Vol. 10. - P. 362-371. 